\title{
Mexican Nuclear Energy: An Opportunity Or A Threat?
}

Flory Anette Dieck-Assad, Ph.D., ITESM-Campus Monterrey, Mexico

\begin{abstract}
On September of 2010, before presenting her report to the Honorable Mexican Congress, the Secretary of Energy, Georgina Kessel, confronted her inner confusion as she was browsing the report of the Federal Electricity Commission (CFE) dated on May 18, 1982, where this company states that because of lack of financial resources, they postponed until further notice the decision of buying a second electricity-generating nuclear plant in Mexico. In that report, they state that the fabulous nuclear-electric program was totally suspended. What were the causes of this historical decision that marked a notable lag in the technological development of the nuclear sector in Mexico?; Could electricity produced through the use of nuclear energy in Mexico be revived as an alternative of clean energy after 28 years of darkness?
\end{abstract}

Keywords: Nuclear Energy; Clean Energies; Nuclear Fission; Laguna Verde; Energy In Mexico

\section{INTRODUCTION}

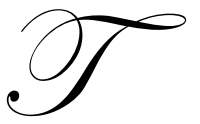

ime is running out for nuclear energy in Mexico. Despite notable progress in the energy sector as a result of the recently approved Energy Reform in Congress in 2009, Secretary of Energy, Georgina Kessel, is concerned. Her concern for energy supply in Mexico increased day by day. PEMEX (Mexican state-owned oil company) will not last forever and we are lagging in the development of alternative energies.

Analyzing the statistics published in 2010, Secretary Kessel was aware that electricity in Mexico is mainly generated from gas and fossil fuels, and their proven reserves will not guarantee the electricity supply for the future generations. Secretary Kessel is concerned about an imminent danger in Mexico, if we do not react on time; people talk about economic crisis, job crisis, financial crisis, moral values crisis, etc., but the government has not faced the gravity of a true energy crisis in Mexico. There is an urgent need to guarantee electricity supply for the development of future generations.

She found a report of the Federal Electricity Commission (CFE) dated on May 18, 1982, where this company states that because of lack of financial resources, they postponed the decision of buying a second electricity-generating nuclear plant in Mexico until further notice. In that report, they state that the fabulous nuclearelectric program was totally suspended. She next called the National Institute of Nuclear Research in Mexico (ININ) to discuss the possibility of reviving the generation of electricity through the controversial nuclear energy in Mexico. ${ }^{1}$

The geopolitical face of the world politics has changed since 1982 - enthusiastically commented the Secretary of Energy to the Director of the ININ. What possibilities does Mexico have to reopen the debate on the production of nuclear energy in the XXI century?; Could you describe the new national and global context in order to start a renewed debate in the Mexican Congress?; Are we prepared?; What technological advances could

\footnotetext{
${ }^{1}$ ININ (Instituto Nacional de Investigaciones Nucleares) is a decentralized federal government institution within the energy sector which actively participates in the international community in the development of $4^{\text {th }}$ generation nuclear reactors and performs basic research on the use of nuclear energy fusion.
}

(C) 2012 The Clute Institute http://www.cluteinstitute.com/ 
guarantee the success of embarking again in the production of nuclear energy?; What are their risks?; Will we have the political support to achieve this?; How do we visualize this source of energy in the light of the XXI century: as an opportunity or as a threat? She asked her colleague for answers based on the findings of his recent research, with the objective of evaluating with more detail the real possibilities of rekindling the nuclear era and deciding on the approach she should take on this topic in front of the Mexican Congress.

Setting up a debate about nuclear energy at the Mexican Congress is just the first step, she concluded with the Director of the ININ, because the most difficult endeavor will be to convince the public opinion about the need to choose nuclear energy to avoid an energy crisis: What would the perception of society be when talking about this controversial energy source?; What strategies should be followed when restarting a nuclear program in Mexico?; Would we lose political strength?; How will history judge our actions?...

\section{IN THE PRESENCE OF EVENTS THAT MARKED THE XXI CENTURY}

Secretary Kessel's anxiety was triggered after she read an article in The New York Times that said that on Tuesday June 15, 2010, U.S. President Barack Obama had summoned Americans to a "national mission". He referred to the specific objective of moving away from reliance on oil and developing alternative sources of energy. He did this in light of the tragedy of the Deepwater Horizon oil platform located in front of the coast of Louisiana, which sank on Thursday April 22, 2010, spilling millions of liters of oil in the waters of the Gulf of Mexico.

This news startled the world because it was the first time President Obama spoke to the national television audience from the Oval Office. One of his statements that impressed Dr. Kessel the most was: "Today, as we look to the Gulf, we see an entire way of life being threatened by a menacing cloud of black crude. We cannot consign our children to this future. The tragedy unfolding on our coast is the most painful and powerful reminder yet, that the time to embrace a clean energy future is now."

The tragedy of the Gulf - thought Secretary Kessel - is giving U.S. President Obama a key opportunity to start an intense marketing campaign on renewable energies such as solar, marine, geothermal, hydroelectric, biomass, wind power, bio-fuels, and nuclear energy. Even though nuclear energy is not renewable, it is included as an alternative because of its low contribution to greenhouse gases and because of the abundant uranium supply. The potential of hydrogen has also been discussed for being a "clean" energy source in the long-run, but it is still at an early development stage for a massive use.

Secretary Kessel spoke up and said "it is true that the transition road towards these new energy sources is long and costly". Secretary Kessel continued reading The New York Times, where it said that it was a certifiable fact that the world has a gigantic renewable energy potential apart from fossil fuels. However, it was also true that it was still insufficiently developed. Experts estimated that in 2010 less than $1 \%$ of its technical potential was used.

Each of the alternative energies present dilemmas that need to be solved - thought Secretary Kessel. The decision about the path to take, about the right energies to choose for developing in any country, is not an easy task and is not exempt from any risks. Among others, three specific dilemmas should be considered: the development costs, initial investment and maturity periods, and the risks derived from its use.

I applaud President Obama's optimism, she thought to herself. However, the road he will have to take is full of challenges and obstacles. As an example of the challenges we could face specifically in Mexico, let's talk about generating electricity using nuclear energy. It is a fact that $60 \%$ of greenhouse gases come from the energy sector, especially the electricity sector. The tragedy on the Gulf has revived the debate about generating electricity by means of nuclear energy. President Obama's "national mission" has transformed into a "world mission" that now involves Mexico. Nuclear energy promoters are taking advantage of the tragedy on the Gulf to deepen nuclear awareness and trigger the discussion of including it as a key material for clean electricity generation. Could this necessarily be the path that Mexico needs to follow?

We cannot deny that the decision taken by CFE, 28 years ago, has left a notorious mark in the history of electricity generation through nuclear energy in Mexico. To be more precise, that decision created an important 
backlog in research and development of nuclear energy in Mexico, a backlog in the training of human resources, a backlog in uranium exploitation, a backlog in the use of this type of energy that requires a great amount of years for maturing and consolidating nuclear projects. How can the interest in electricity produced through the use of nuclear energy in Mexico be resurrected in the year 2010 after 28 years?

\section{HISTORICAL BACKGROUND}

Secretary Kessel decided to do some research on her own simultaneously to the one made by the Director of the ININ; she wanted to fully understand the situation before making the first move in the debate. She next located articles that would help her validate the report she was going to receive from the Director of the ININ.

Who would have thought that the scientific research and findings of the 1930s placed me in the middle of this grave dilemma of deciding about electricity generated using nuclear energy?

Indeed, it was in the 1930s when Enrico Fermi and his colleagues produced the first artificial nuclear fission when bombarding more than 60 elements with neutrons, among them, $U$ isotope (Uranium 235) and discovered that nuclei from other elements such as "Barium" appeared as a result. That was the moment when they discovered "fission", and they concluded that this was the result of dividing the uranium nuclei.

Later on, 1935 Nobel Chemistry Prize Jean Frederic Joliot-Curie and his wife, who synthesized new radioactive elements, discovered that besides "Barium" (Ba) and "Krypton" $(\mathrm{Kr})$, the fission of the uranium nuclei emitted secondary neutrons that generated a feasible chain reaction to generate the energy that we now call atomic energy.

The analysis of nuclear fission and the generation of energy during this process, continued in 1938 by Otto Hahn and Fritz Strassmann based on the work of Hahn and Lise Meitner in previous years. For this discovery, Otto Hahn received the 1944 Chemistry Nobel Prize, whereas Meitner's work was never recognized.

Now Secretary Kessel remembered the reason why Europe, especially France, became the leader of atomic energy. She drew a diagram she had once found on the Internet. Staring at it, she realized that even though technology has made important breakthroughs in the last years, fission remains the same thing (Figure 1).

While drawing the diagram of the Uranium 235 fission phenomena (the rupture of the uranium nucleus), she remembered that the appearance of new neutrons gives us the possibility of producing a chain reaction that generates atomic energy. Therefore, each newly emitted neutron as a result of the original fission can produce fission of a new uranium nucleus. However, these emitted neutrons are characterized by having a very high velocity that should be decreased in order to be able to split a new uranium nucleus. To stop this velocity, moderators are created with the objective of surrounding the atoms with other smaller elements such as water, carbon, lithium, etc.

Likewise, the reactor needs to be refrigerated so that it does not get too hot during the chain reaction. In this way, depending on the combination of the type of fuel, the type of moderator, and the type of refrigerant, different types of atomic reactors that generate electricity emerge. Some of the most common reactors are: the PHWR (Pressurized Heavy Water Reactor), the PWR (Pressurized Water Reactor), the BWR (Boiling Water Reactor), the GCR (Gas Cooled Reactor) which is cooled by Carbon Dioxide and moderated by Graphite, and the LMFBR (Liquid Metal Fast Breeder Reactor) which is cooled with Sodium. 
A slow-moving neutron ......

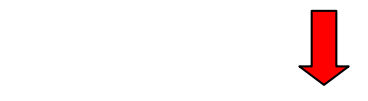

...impacts an uranium nucleus.....

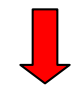

........destabilizing it.

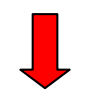

This nucleus is divided into two lighter nuclei along with....

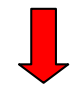

... the emission of 2 or 3 high-velocity neutrons, the generation of gamma radiation, and kinetic energy $(200 \mathrm{MeV})$ which is finally transformed into heat (energy). This heat moves the turbine in a nuclear reactor which in turn moves the generator to produce electric energy.
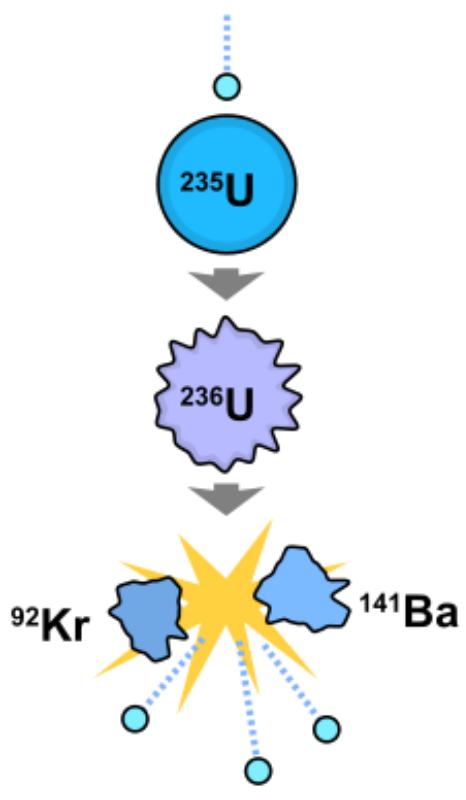

Figure 1. Uranium 235 fission phenomena

Secretary Kessel looked over the last report she had about the only Nuclear Center in Alto Lucero, in the state of Veracruz, Mexico - the Laguna Verde Nuclear Plant. She confirmed that it has 2 electricity generating units of 682.5 MW each. The reactor brand is General Electric (BWR-5), a boiling water reactor, which use natural water as moderator and cooler and the enriched uranium as fuel. Unit \#1 started commercial operations on July 29, 1990 and Unit \#2 started operations on April 10, 1995.

The key points in the process of determining the dilemmas to be solved before deciding to promote electricity generation by means of nuclear energy to the Mexican Congress appear in her mind. - I have to find the answers to each and every one of these dilemmas before defining my position on the increase in electricity through the use of nuclear energy in Mexico.

\section{MEASURING RADIATION}

Radiation is all around us. For example, light is a type of radiation we can see, heat is a radiation we feel, ultraviolet rays from the sun and medical X-rays are not visible, but clearly detectable. The "Rem" is a unit of measure of radiations. CFE stated that the degree of natural radiation received by a regular living being is an average of 125 and 135 millirems (mrem) per year and the dose of artificial radiation (i.e. using a watch, X-rays, jet-plane travelling, etc.) is of about $55 \mathrm{mrem}$.

A nucleoelectric central is designed so that, during normal operations, it emits radiation that is less than 5 millirems (mrem) per year. This would be the equivalent of $3 \%$ of the radiation that any human being would normally receive in their everyday activities. That is possible because of the adoption of strict safety regulations in construction and in the operation of a nuclear plant; these regulations are also supervised by specialized regulatory institutions in each country. If there are excellent safety regulations, what would be the reasons why a nuclear plant could be regarded as a significant risk for the population and for the environment?

Secretary Kessel continued reading a report on Laguna Verde that explained the four elements required for a maximum security nucleo-electric plant to be installed which are: 
a) The choice of the site for its construction: it cannot be near active geological faults, or in an earthquakeprone land. The site cannot be in a region prone to hurricanes, tornados, or tsunamis to avoid loss of water stagnation (avoid water filtration) in the containment structures.

b) The specifications of its design (reactor, refrigerant, and moderator) that show when to stop the operation of the atomic reactor if there were any safety risks in the nucleo-electric plant.

c) To have guarantee and control systems that assure the excellence in construction according to the building specifications and avoid the usage of components that do not meet the established norms.

d) It is also important to make sure that, once the plant is constructed, the operation should be monitored and controlled throughout its life by expert personnel, and inspected by their respective authorities.

How should the facilities be constructed in order to maintain a high safety level?; Are there any risks of accidents?; What would the consequences be? Dissatisfied with what she had found out, Secretary Kessel wanted more evidence on accidents occurring in other nuclear plants around the world; she started browsing in her computer and found the following:

- $\quad$ On March of 1979, the "Three Mile Island" (Pennsylvania, U.S.A.) nuclear facility had a serious accident after its first year of operations, caused by wrong decisions taken as a result of ill-informed interpretations.

- $\quad$ On April 26, 1986, the worst nuclear accident in world history happened in the nuclear plant in Chernobyl, Ukraine triggered by a chain reaction of human errors during the demonstration tests within the nuclear facility.

- $\quad$ On October of 1989, the nuclear incident of Vandellós I in Spain took place. A fire in the electric generator caused a mechanical failure, which flooded the cellar of the reactor with sea water and made some security systems inoperable.

- On September of 1999, there was an accident in the uranium fuel treatment plant which is property of the company JCO in Tokaimura, Japan.

- $\quad$ On March 11, 2011, after the Tohoku, Japan earthquake and tsunami, the Fukushima nuclear plant had a major accident.

\section{WHERE IS THE NUCLEAR WASTE?}

The production of nuclear energy generates solid radioactive waste (tools, clothes, work equipment, and mainly fuel rods extracted from the reactor because they reached the end of their useful life), liquid waste (chemical residues and mixed water with detergents) and gaseous waste (non-condensed gases enclosed with vapor and precisely separated from the vapor in the condenser).

Leafing through The New York Times issue of May 10, 2010, Dr. Kessel read an article by Dennis Overbye who stated that there are somewhere between 250,000 and 300,000 tons of high-level radioactive waste already in the world, much of it in pools on the sites of nuclear power plants where the fuel rods have to cool for years before they can be put into containers. Georgina remembered the most recent documentary from Danish producer Michael Madsen, titled "Into Eternity", where he stated that a nuclear waste container should be "a place we should always remember to forget".

Secretary Kessel remembered that the Laguna Verde reactors are endowed with abatement pools capable of storing fuel used-up after ten years of operation; however, Laguna Verde plant has already been operating for 20 years and is still storing these fuels. After this temporary storage, we would need to make a definitive decision: we need to place these radioactive waste in special containers designed to be preserved for thousands of years and ship them to a final underground Radioactive Residue Facility (RRF), which should be constructed in a desolate place where geological studies prove that there is stability of the subsoil structures for millions of years.

Secretary Kessel read a CFE report stating: Given the scarcity of economic resources, there are other possibilities that involve storing the waste in containers at ground level in a suitable facility for 30 or 40 years and sending them afterwards to the RRF. This option would be less expensive because it would delay the construction of the RRF. The CFE report also stated that the used-up fuels stored in the containers could be sent to reprocessing plants, which would be the most expensive alternative, but the costs could be compensated with the production of 
new Uranium and Plutonium to be sold, reused in the atomic reactor, or even to recover materials that could be useful for industrial, medicinal, and agricultural purposes. Georgina remembered the comment made by the ININ Director when he said that the world is already operating with more than 100 facilities designed to store low and intermediate radioactive level waste which, after 300 to 500 years, will achieve sufficient stability to be exempt from an institutional supervision.

An already approved project to construct a radioactive residue cemetery in the Yucca Mountain in Nevada, U.S.A. is ready to be launched. At the moment, the National Research Council (NRC) requested an increase in quality and endurance of this cemetery in order to show performance reliability for 10,000 years, even though the original request was for 1 million years. - Highly contaminating medium-life radioactive waste may take many years to decay and to abate radioactivity. Therefore, they should be stored with extreme caution, but where? What will we do with the Mexican Nuclear Waste? This is another difficult dilemma to discuss.

Secretary Georgina found that, besides the Yucca Mountain case, Canada, Belgium, Switzerland, Sweden, and Finland have developed interesting solutions to this dilemma. For example, Finnish engineers are digging a tunnel on a wooded island more than a hundred miles northwest of Helsinki, in the town of Eurajoki, Finland. When it is completed by the year 2020, it will corkscrew three miles $(5 \mathrm{~km})$ in and reaching a depth of 1,600 feet $(480 \mathrm{~m})$, where the used fuel rods from Finland's nuclear reactors - full of radioactive elements - are to be sealed away forever or at least 100,000 years. $^{2}$

Georgina Kessel continued reading Dennis Overbye's article where he commented that "it might seem crazy, if not criminal, to force 3,000 future generations of humans to take care of our poisonous waste just so that we can continue running our electric toothbrushes. But it's already too late to wave off the nuclear age, and Mr. Madsen's film comes at a perfect time to join a worldwide conversation about what to do with its ashes". Dennis Overbye continued reflecting: "We're always reading about time capsules being buried, but we rarely hear about them being dug up and opened. One of the most famous archaeological discoveries of modern times, the terra-cotta army buried with Qin, the first Chinese emperor, outside the city of Xian, was made by a farmer digging a well".

However, if we follow Madsen's motto of considering the radioactive waste cemeteries as "a place we should always remember to forget", an ethical dilemma arises: What will happen with the "ethical duty" of warning future generations about the existence of these forgotten cemeteries? Based on Dennis Overbye's opinion, if in fact, these containers were rediscovered a few hundred years or a few thousand years from now, could we imagine our descendants' reaction at having been left with such a nasty surprise? A radioactive cemetery is a place we "cannot" and "will not" forget! It is our ethical duty to document it!

\section{WHERE ARE THE ECONOMIC RESOURCES TO FINANCE THE PROJECT?}

Secretary Kessel then remembered the famous quote from the President of the former Atomic Energy Commission, Lewis Strauss, who in 1954 stated: "Thinking that our children will be able to consume low cost electricity generated by nuclear means is no utopia anymore". - Could we support the same statement in today's $21^{\text {st }}$ century?

The initial investment is extremely high. Are there going to be funds for it? Even though nowadays atomic energy is not the cheapest electric energy produced with respect to the traditional thermoelectric plants, there are possibilities of improving the technical performance. Cintia Angulo, President of the Mexican Chapter of the World Energy Council, estimated that a newly constructed nuclear electricity plant would cost around $\$ 4,500$ million dollars, keeping in mind the long periods for its maturing and start-up operations (the first study group for examining the technical and economic feasibility of Laguna Verde in Veracruz was formed in 1965; the first unit received the operating license until 1990 and the second unit in 1995). According to the figures provided by the Mexican Federal Electricity Commission (CFE), producing one kilowatt-hour of electricity with nuclear energy at the year 2008 market prices would cost $\$ 0.91$ pesos, while using natural gas, coal, or fuel oil would be $\$ 1.20, \$ 1.30$,

\footnotetext{
${ }^{2}$ The place is called Onkalo ("hidden", in Finnish) and is the main issue addressed in the documentary "Into Eternity" from Danish producer Michael Madsen in 2010. 
and $\$ 1.33$ pesos respectively. Hydroelectric energy would be the cheapest ( $\$ 0.55$ pesos per kilowatt-hour); however, its application is doubtful because it depends on the optimum water storage levels in dams. In terms of efficiency, if the world level of kilowatt-hour produced by installed kilowatt is considered, then nuclear energy produces 66 times more than thermal energy and more than twice as much as hydroelectric plants and almost triple the one produced in geothermal plants.

The Mexican Energy Regulatory Commission (CRE) supports industrial chambers' viewpoint that the price of electric energy has increased more in Mexico than in the United States from 30\% to 35\% during the first ten years of the $21^{\text {st }}$ century. However, this is due because nearly $80 \%$ of U.S. electricity is produced with coal and nuclear energy whereas this same percentage in Mexico is produced with fuel oil and natural gas which have also increased its price historically during the first years of this century. For these reasons, the only available alternative to reduce electricity costs in Mexico is to generate it with nuclear energy. Even though the cost of installing a nuclear plant is too high, the operation of the plant is not, because using uranium in the production is cheap.

In case that Mexico decides to implement a nuclear program, 10 reactors would have to be constructed in 30 years; the first one should start operating in the year 2018, according to CFE estimations. Constructing 10 reactors is equivalent to adding 12,000 megawatts of electricity (the actual installed capacity of CFE is 50,403 megawatts) at an approximate cost between $\$ 3,000$ and $\$ 3,500$ dollars per installed kilowatt, stated Pablo Mulas from the Institute for Electric Research in Mexico.

But, with the world economic crisis and a slow recovery, where will Mexico find the resources it needs for these Electric Plants?; Which projects will Mexico leave unattended in order to construct a new nuclear plant for electricity?; What will the opportunity cost?; Will the federal authorities understand it?; Will Mexicans know about it?; How much time will Mexico take from constructing the nuclear plant to the moment of generating electricity?; Will Mexico have the necessary time to wait? Just as Carroll L. Wilson wisely said once: "Time is our most valuable resource. It should be used as wisely as energy."

\section{WHERE IS THE BEST TECHNOLOGY?}

Without doubt, there are successful cases in nuclear energy generation such as in U.S.A., France, Chile, Germany, Spain, and Belgium. Germany stunned the world on June 14, 2000 when it announced the agreement to gradually withdraw nuclear energy from the country. However, Germany surprised the world once again when its Federal Environmental Agency declared on July 2010 that this country will strive to generate all of its electricity from renewable sources of energy as of the year 2050 and become the first industrialized economy to abandon the use of fossil fuels. To achieve this, on September 5, 2010 the German government announced that it will extend the useful life of its 17 atomic energy plants by 8 years for its oldest facilities and by 14 years for its newer ones, and simultaneously invest between $\$ 2,000$ and $\$ 3,000$ million Euros for renewable energies.

Sweden, which abandoned nuclear power after less than $20 \%$ of Swedes approved of it in a referendum in the 1980s, changed its mind. On April 2010, they announced plans to begin building new nuclear reactors, adding to the 10 that are already in operation. Claes Thegerstrom, a nuclear physicist who is the chief executive of the Swedish Nuclear Fuel and Waste Management Company (SKB), attributed the new attitude of Swedes toward nuclear energy, to the fear of global warming. In the 1980 s nobody mentioned $\mathrm{CO}_{2}$ as the major cause of global warming. - In Sweden it now appears as if nuclear reactors are less scary than global warming and its consequences, Georgina thought.

The philosophy of U.S. President Barack Obama's government with respect to nuclear energy is that, in terms of global warming threat, nuclear energy is a clean energy similar to solar and wind energy, but with the great difference that it can achieve a truly important economy of scale. U.S.A is the country with the highest nuclear electric capacity in the world. France is the most dependent on this energy source because it represents almost $80 \%$ of its primary energy. China appears to be the country with highest potential for nuclear development in the near future. In year 2010, from the 56 reactors that are being constructed, 21 belong to China, 6 to Korea, and 5 to India. 
In Mexico, President Felipe Calderon's administration does not accept nuclear development, especially because of a slow economic growth where energy needs grow at a slower rate than countries like Brazil or China. Nevertheless, the nuclear era is here to stay; that is why the CFE has recommended Mexico to incorporate the new generation of nuclear mini plants developed by U.S.A. and India. This will have the advantage of decreasing dependency on fossil fuels, furnish diverse geographical areas, and mitigate the effects of climate change. These are going to be low-scale modular plants with nuclear reactors of about 100 megawatts, higher safety levels and require lower installation costs than traditional plants.

On June 2, 2010, Felipe de Jesus Cantu, President of the Energy Commission of the Federal Chamber of Deputies, presented the details of these new nuclear reactors: they work with Thorium, instead of Uranium or Plutonium which are even more scarce, and by means of nuclear fission they generate highly pressurized vapor which is channeled for turbine rotation and electricity generation. A 25 megawatt plant with a reactor of this sort requires approximately $750 \mathrm{~m}^{2}$ of space. The U.S. company Babcock \& Wilcox develops reactors with capacity between 125 and 750 megawatts, with a 4.5 year cycle without recharging nuclear fuel, a useful life of 60 years, and a construction period of 3 years; these reactors will be up and ready for commercial use towards the year 2018 .

Secretary Kessel considered the dilemmas once again. What technology should we use?; Will we continue using the one from Laguna Verde which is Boiling Water Reactor (BWR), or are there other less expensive options with improved technology in the market?; Is the new generation of reactors already available?; How feasible would it be to use $4^{\text {th }}$ generation atomic reactors?; How has the technology advanced on this matter?; Will we increase the power of the current reactors of Laguna Verde?; Will we support the nuclear trend of smaller reactors?; What would be best: construct new nuclear plants for electricity or extend the useful life of the existent plants?

\section{EPILOGUE}

Secretary Kessel's main conclusions are:

- It is important to consider the possibility of extending the use of nuclear energy in Mexico taking into account the available options in technology, costs, long-term maturation periods of the projects, safety regulations, political willpower, and profitability. We cannot embrace ourselves irresponsibly by the craze of nuclear energy in the world.

- We cannot deny that nuclear energy is the only energy source that can generate the sufficient volume to allow energy consumption per capita to continue growing - especially in the poorest countries - and control the growing greenhouse gas emissions.

- Mexican activists, in favor of nuclear energy, have to be aware of the wrongful decisions Mexico made in the past, in order to responsibly face the lags caused by these historical decisions and avoid making the same mistakes again.

- $\quad$ Mexico is going through a rough period of instability and violence. Talking about terrorism seemed so farfetched years ago, but now things have changed. If we want to promote the generation of nuclear energy, we need to make sure that there are strong safety regulations. This is not an easy decision to make!

- $\quad$ The geopolitical face of the world has changed since the decision taken by CFE in 1982. So, what possibilities will Mexico have to trigger a new debate towards producing nuclear energy in the $21^{\text {st }}$ century?; Are we aware of the responsibility required in the Mexican Congress when talking about the nuclear debate considering the new circumstances in Mexico and the world?; Are we going to be prepared for this?; What technological advances could guarantee the success of reviving nuclear energy production in Mexico?; What are its risks?; Will we have the strength and the political willpower to achieve it?; How could we visualize nuclear energy in the $21^{\text {st }}$ century: as an opportunity or as a threat to the safety of Mexico and its citizens?; What would be the most convenient basket of energy resources to develop in Mexico?

Secretary Kessel is still trying to put her ideas in order. Providing a proposal for nuclear energy is a very complicated challenge. It looked as if each argument related to nuclear energy was debatable and questionable. Even though Mexico already has a nuclear plant, its energy generation capacity is minimal compared to hydrocarbons. Constructing additional nuclear plants in Mexico was previously considered unfeasible because of the high costs 
involved. She finally concludes that we were resting upon an oil dream, but it is now time to wake up, and the reality is not very promising.

Mexico could consider solar, wind, or hydroelectric energy as options, but none of them could satisfy the energy needs for the whole country due to its low potency or power. Nuclear energy seems to be the best option, but will it be affordable, or will it have social support, or is it really safe? The Mexican Government would not want to imagine Mexico submerged in a nuclear disaster.

The Secretary of Energy knew that she had a historic opportunity in her hands to change the energy policy of Mexico; the national welfare of present and future generations depend upon this monumental responsibility. She had the duty of creating a clear and convincing proposal in order for it to be approved by the Mexican Congress as well as obtaining social support. This unresolved dilemma is still open and its solution will rest upon the hands of future administrations.

\section{AUTHOR INFORMATION}

Dr. Flory Anette Dieck Assad, Instituto Tecnológico y de Estudios Superiores de Monterrey, Ph.D. in Finance from Tulane University (2003). McGraw-Hill published her first book "Financial Institutions" (2004). Invited lecturer in Mexico, Chile, U.S.A., Canada and Europe, got the "Best Lecture Award" in 2004, 2008, 2010 and 2011. She has more than 80 publications in national/international magazines, reviews, and journals. She got the "Prize to Education and Research 2007, 2010 and 2011". Certified in the Case Method (2007), has written academic cases in energy and ethics. Texas A\&M University Press published her second book titled: "Energy and Sustainable Development in Mexico" (2005), honored with the "National Romulo Garza Award for the Best Written Book" (2008). She received the highest recognition for her academic career as Tenured Professor at ITESM in September 2011.E-mail: fdieck@itesm.mx

\section{REFERENCES}

1. Campos Aragón, Leticia (2009). El Resurgimiento de la Energía Nuclear: ¿Una Opción para el Cambio Climático y para los países emergentes?, Siglo Veintiuno Editores.

2. $\quad$ Comisión Federal de Electricidad (1989), Del Fuego a la Energía Nuclear, México.

3. Lilley, John (2001). Nuclear Physics. Principles and Applications. John Wiley \& Sons, Ltd. ISBN 0-47197936-8.

4. MIT (1977). WAES (Workshop on Alternative Energy Strategies), Energy: Global Prospects 1985-2000.

5. Overbye, Dennis (2010). Finland's 100,000-Year Plan to Banish Its Nuclear Waste, The New York Times, May 10.

6. $\quad$ Smith, Rebecca (2010). Small Reactors Generate Big Hopes, The Wall Street Journal, February 19.

7. Tagliabue, John (2010). A Town Says 'Yes, in Our Backyard' to Nuclear Site, The New York Times, April 6.

8. Teeghman, David (2011). A sea change: nuclear reactor on ocean floor, Energize Weekly by EUCI, January 28, Vol 4, No. 4, USA.

9. The New York Times (2010). Obama Calls for New Focus on Energy, June 16.

10. United Nations (2005). Energy Statistics Yearbook, 2005. 


\section{NOTES}

